\title{
Analytical approaches to investigating seabird-environment interactions: a review
}

\author{
Yann Tremblay ${ }^{1, *}$, Sophie Bertrand ${ }^{1}$, R. William Henry ${ }^{2}$, Michelle A. Kappes $^{2}$, \\ Daniel P. Costa ${ }^{2}$, Scott A. Shaffer ${ }^{2}$
}

${ }^{1}$ Institut pour la Recherche et le Développement, Centre de Recherche Halieutique et Méditerranéenne et Tropicale, UMR 212, Avenue Jean Monnet-BP 171, 34203 Sète cedex, France

${ }^{2}$ Department of Ecology and Evolutionary Biology and Institute of Marine Sciences, University of California Santa Cruz, Santa Cruz, California 95060-5730, USA

\begin{abstract}
A goal of seabird ecology is to relate the physiology, population dynamics, distribution and behaviour of seabirds with their biotic and abiotic environments. One of the most challenging aspects is to understand how seabirds interact with their environment when direct observations are not always possible or practical. In the present paper, we reviewed 218 published studies that examined associations between seabird distribution, behaviour and their environment, in order to assess current trends, weaknesses and the future directions of research. Based on the number of publications, it is evident that the field is growing rapidly and that methods for evaluating seabird distribution are becoming increasingly more sophisticated and are changing from Eulerian (grid-like) to Lagrangian (particle-like) data types. This has been accompanied by a reduction in the spatial and temporal scale of observation, where, in most cases, no behavioural information is inferred from Lagrangian data; instead they are often used as if they were Eulerian data. In parallel, environmental remote sensing is becoming more common; however, we did not record significant changes in the statistical approaches used to describe seabird distributions and used to link them with oceanographic variables. In particular, despite the spatially explicit nature of the data, spatial statistics have rarely been used. The vast majority of studies used environmental variables that described water masses (descriptive approach), whereas a few studies determined oceanographic features that enhance prey availability to seabirds (process-based approach). Future studies could enhance their ecological interpretation of seabird-environment interactions by making greater use of ad hoc statistical approaches that facilitate appropriate pattern detection (e.g. area-restricted searching pattern for birds, mesoscale patterns for environment). Furthermore, appropriate hypothesis testing and modelling that accounts for the spatially explicit, multiscale and multivariate nature of the interaction between seabirds and their habitats is recommended. Although quantitative methods currently exist (but are rarely used), further application could greatly improve our understanding of the processes linking seabird distribution to their environment.
\end{abstract}

KEY WORDS: Habitat · Top-predators · Seabirds · Interactions · Surveys · Tracking · Methods · At-sea ecology

Resale or republication not permitted without written consent of the publisher

\section{INTRODUCTION}

Marine ecosystems are often difficult to study; as so aptly stated by Monod (1991): nothing is more difficult to study than something you cannot see. Furthermore, studies of seabird foraging ecology are complicated by the great distances covered by foraging marine birds coupled with the associated difficulty of observing prey distributions far-out at-sea. As a result, the functional relationships between seabird behaviour and their biotic and abiotic environments remain elusive. The first investigations into seabird ecology (e.g. Ashmole 1971) relied on land-based observation of seabird behaviour and diet studies (Ainley et al. 1981, Ainley 
1990). Observations of seabirds at-sea were later undertaken from opportunistic or dedicated vessel surveys (Haney 1985a, 1987a, Hunt 1991, Hunt et al. 1992, Veit et al. 1993). More recently, traditional land- and ship-based observations have been complemented by modern observation technologies, the implementation of which now provides powerful 'eyes' to observe the ecosystem: satellite remote sensing, acoustic surveying, or miniaturized electronic tagging (Haney 1985b, 1986c, Ainley et al. 1995, Wilson et al. 2002, Cooke et al. 2004, Burger \& Shaffer 2008). Undoubtedly, the field of seabird ecology has been burgeoned by this rich set of scientific approaches; to our knowledge, no critical evaluation of the tools commonly employed to link seabird locations and their environment exists.

The goal of the present paper was to review and summarize how scientific approaches and methodological tools in seabird ecology have evolved. In this review, we also highlight state-of-the-art techniques for evaluating seabird distribution and habitat associations, as well as speculate on promising future directions for research. It is important to note that, contrary to classical reviews, our goals were not to be instructive about methods per se, but rather to highlight utilization trends by authors in the field and to speculate on how these trends might relate to changes in conceptual approaches.

\section{MATERIALS AND METHODS}

This work is based on the analysis of contents from published research articles. Research articles were selected with the 'ISI Web of Knowledge' (Thomson Reuters) search engine, using the following search criteria:

Topic $=\left(\right.$ (seabird ${ }^{*}$ AND (distribution OR abundance OR track* OR at-sea observation)) AND (ocean* OR front* OR edd* OR prey))

Timespan=All Years

Refined by: Subject Areas= $($ Environmental Sciences \& Ecology OR Zoology OR Marine \& Freshwater Biology OR Oceanography OR Biodiversity \& Conservation OR Fisheries OR Behavioral Sciences OR Evolutionary Biology)

These search criteria returned 1286 papers from which we removed all papers that focused exclusively on toxicology, parasites, pollution, population trend or breeding performance, predation and interaction with terrestrial mammals, diet and chick growth, or prey biology. The remaining 461 papers were collected and further evaluated for relevance to the topic.

Papers were considered relevant and included in subsequent analyses if they reported both positional data of seabirds and at least one associated environ- mental variable. The presence of fishing vessels or fisheries effort data were considered environmental variables. This yielded a total of 218 publications on which our review was based. We recognize that some relevant publications may have been missed (particularly book chapters, books and unpublished reports); however, our review should be representative of research in the field.

The following questions were used to characterize the analyses presented in the reviewed manuscripts:

- How was the distribution of seabirds obtained?

- How was the distribution of seabirds modeled/ summarized/analyzed?

- How were the environmental variables obtained?

- Which environmental variables were used?

- How was the association between seabird distribution and environmental variables characterized?

Responses to these questions were then summarized in order to quantify the methodological techniques used in the reviewed papers. In order to analyze temporal trends in publication and methodological techniques, we separated publications into $5 \mathrm{yr}$ bins, as a compromise between the time resolution and the number of publications in each bin (as shown in Fig. 1).

We have created a bibliographic library of the relevant papers, and interested parties can contact the corresponding author for copies.



Fig. 1. Temporal distribution of the 218 research articles analyzed in the present study (see 'Materials and methods' for selection criteria) 


\section{RESULTS}

Research on free-ranging seabirds and ecology atsea has increased from a few papers a year in the 1970s, to over $15 \mathrm{yr}^{-1}$ today (Fig. 1). This trend coincides with the increased availability of personal computers, a change that impacted not only the way data were collected, but also the level of analytical sophistication employed.

\section{Seabird locations}

At-sea, ship-based observation of seabirds has been the traditional method of determining seabird distribution. Across all years surveyed, at-sea surveys and observations of birds at sea have been the dominant form of study (Fig. 2). Ship-based observations can be further divided into 2 methodological groups: the classical transect method and the punctual observation method. This later method typically represented seabird observations performed by observers on board vessels during fishing operations (Abrams 1983, Abello et al. 2003). Punctual observations represented $<10 \%$ of the number of studies using ship-based observations in all 5 yr bins since 1985, except in the 2005 bin, in which it rapidly increased to $23.5 \%$ of the number of papers using ship-based observations.



Fig. 2. Temporal distribution of methodological approaches used to obtain positional observations of seabirds at-sea in 218 relevant research articles. Bins span $5 \mathrm{yr}$, and numbers indicate the total number of occurrences of the methodological techniques, not the number of papers. The category 'other' includes land-based counts, plane transects and bycatch
In contrast to traditional ship-based methodologies, seabird distributional data have also been obtained using microprocessor-based transmitting or data logging tags. This methodology consists of calculating animal locations using electronic tags directly attached to the animal. This includes satellite tracking (Argos transmitters [Berrow et al. 2000], GPS receivers [Awkerman et al. 2005]), global location sensing (GLS) based on light (archival light-level tags; Phillips et al. 2006), radio telemetry (VHF transmitter; Furness et al. 2000) and dead-reckoning (speed/bearing recorders; Benvenuti et al. 1998). The use of electronic-based methodologies, which appeared in the literature in the early 1990s, has continued to increase ever since, due to rapid advances in related technologies (Fig. 2) (Wilson et al. 2002). The Argos tracking system was the only electronic methodology used in papers published in the mid-1990s, and remains the most common method used ( $>67 \%$ of papers using electronic-based methods). However, its relative application has decreased recently as GPS-based and GLS-based tagging studies increased, both of which equally contributed $26 \%$ of all papers using electronic methodology in the 2005 bin. VHF and dead-reckoning methods appeared marginal, and therefore we do not detail their contribution here. With the advent of daily diary tags (Wilson et al. 1991, 2006, 2007, 2008), it is conceivable that dead-reckoning tags will be used more often in the future.

Other methods to determine seabird distribution have also been reported in the literature (e.g. plane transects, land-based observations and bycatch during fisheries operations), but these methods contributed minimally to the number of published research papers (Fig. 2). The apparent importance of the 'other' group in the 1980 bin results from small sample size bias (only 7 papers in this category).

Seabird distribution data have been reported in the literature as simple locations or density grids, as well as using more quantitative indices such as computing kernel densities (van Franeker et al. 2002, Awkerman et al. 2005, Clarke et al. 2006). The simple display of distribution data has been much more commonly used than quantitative indices, with proportions ranging from 80 to $100 \%$ of the number of papers for any given 5 yr period.

\section{Environmental variables}

Environmental data collected in situ are found in the majority of studies in all 5 yr bins (Fig. 3). The use of aerial surveys, data from the literature, animalborne sensors, or general geographic knowledge to extract environmental information does not show a 


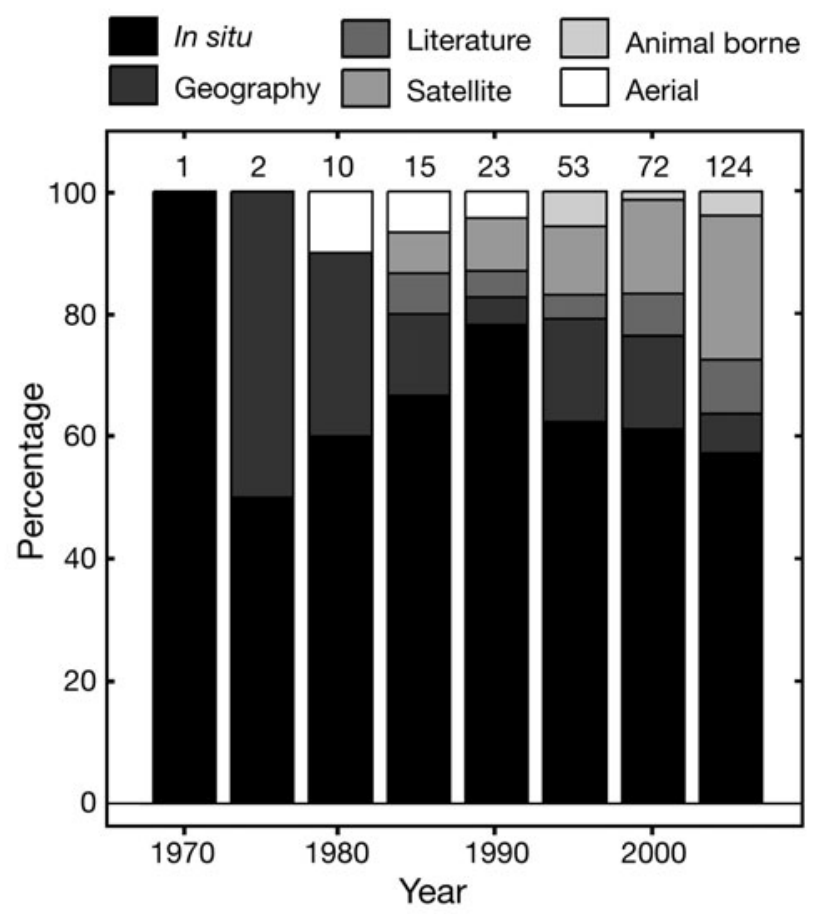

Fig. 3. Temporal distribution of the methodological approaches used to collect environmental data in the 218 relevant research articles used in the present study. Numbers indicate the total number of occurrences of the methodological techniques, not the number of papers clear trend in time (Fig. 3). The relative contribution of satellite remote-sensing data increased at a relatively slow rate (2.3 more papers per 5 yr) between the mid-1980s and the mid-1990s, but has now become much more common in the last decade $(6.0$ more papers per bin). The trend has increased exponentially (data not shown) and does not show signs of slowing down $(23.4 \%$ of occurrence in the 2005 bin, the largest so far).

We identified a total of 101 different environmental variables in all of the 218 research articles. These variables were regrouped into 22 'variable types' based on the type of environmental parameters involved (Table 1). The relative utilization of these variable types is extremely unbalanced, with 4 types (temperature, salinity, prey and zone) representing $>50 \%$ of all variables (Table 1 ). The remaining 18 types contributed $45 \%$ of all variables, and included extremely diverse variables, from dissolved oxygen to bathymetry (Table 1). The contribution of variables describing an oceanographic structure (grouped as 'mesoscale features'; Ribic et al. 1997, Ainley et al. 1998, Nel et al. 2001) and thought to have a positive effect on the availability of prey to seabirds, such as a front or an eddy (as opposed to variables physically describing a water mass), is relatively minor $(4.8 \%$ of all variables; Table 1).

Table 1. Description and relative contributions of environmental variables used in 218 research articles linking seabird positional information with environment characteristics. Variables are ranked by relative contribution

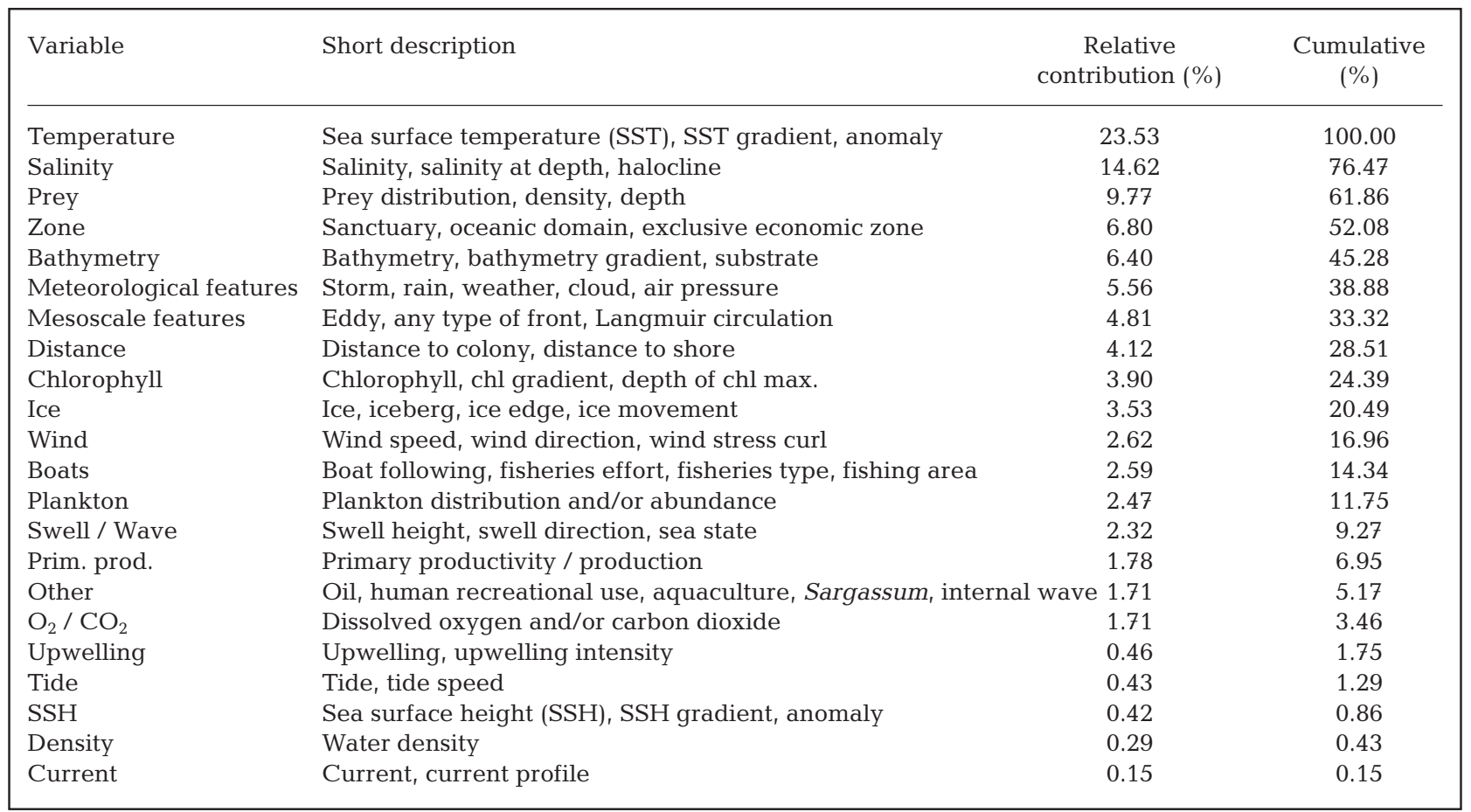




\section{Association between seabird distribution and environmental variables}

We categorized a total of 43 different statistical techniques in all selected papers that we grouped into 6 broad categories (Fig. 4, Table 2): (1) qualitative approaches (e.g. mapping, geographic information systems [GIS]) aimed at displaying the data and supporting pertinent hypotheses for further testing (Harrison 1982, Joiris 1991, Hull et al. 1997, Ollason et al. 1997), (2) classic hypothesis-testing approaches examining patterns between areas, species, time periods, etc. (Abrams 1985, Garthe 1997, Skov \& Durinck 2000, Roycroft et al. 2007), (3) classic statistical modelling approaches (e.g. linear regression, correlation, generalized linear or additive models [GLM-GAM]) examining functional relationships between distribution and environmental variables (Ribic \& Ainley 1997, Spear et al. 2003, Olivier \& Wotherspoon 2006), (4) spatially explicit approaches (e.g. point process methods, geostatistics) quantifying spatial co-occurrence and coherence between different ecosystem processes (Russell et al. 1992, O'Driscoll 1998, Navarro \& Gonzalez-Solis 2007 , Villablanca et al. 2007), (5) multivariate approaches (e.g. principal components analysis [PCA], classification trees, etc.) examining complex, non-linear relationships in seabird distribution patterns (Ballance et al.

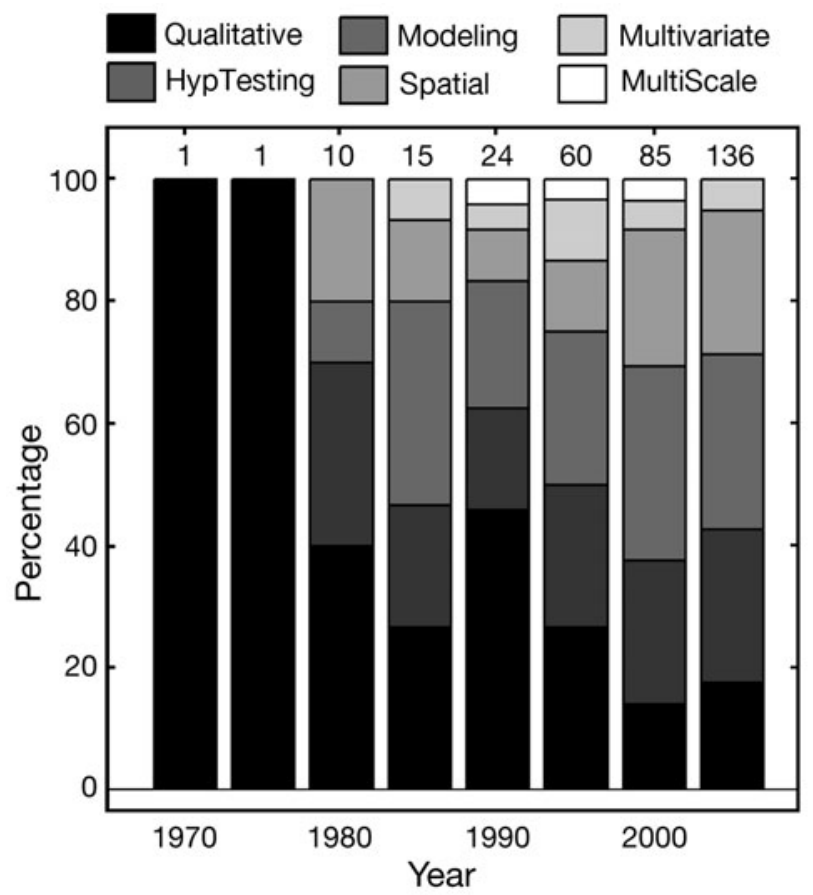

Fig. 4. Temporal distribution of the statistical approaches used in 218 relevant research articles associating seabird locations and environmental variables. Numbers represent the number of occurrences of statistical approaches in each bin, not the number of papers. See Table 2 for further details




1997, Karnovsky et al. 2003, Weichler et al. 2004, Hyrenbach et al. 2007) and (6) multi-scale approaches (e.g. wavelets, fractal geometry) investigating ecological functional relationships (Russell et al. 1992b, Logerwell et al. 1998, Mehlum et al. 1999, Swartzman \& Hunt 2000) that are known to change with scale (Levin 1992).

The analytical methods used are often predicated by the data available. However, long-term, high-resolution data for seabirds along with environmental data (sea surface temperature [SST], El Niño Southern Oscillation [ENSO] index, chlorophyll, etc.) of marine ecosystems are increasingly available. Therefore, it is surprising that we did not observe increased use of more powerful, spatially explicit, multivariate and multiscale approaches. In fact, the use of the 6 approach categories did not show any clear trend with time.

All approaches have been used in a fairly constant way since the 1980s (Fig. 4). Multivariate and multiscale analyses combined represented $<10 \%$ of all analyses in any given $5 \mathrm{yr}$ bin. Spatial approaches have tended to be used more frequently since the mid1990s, but only 1 out of 5 spatial analyses actually used spatial statistics. The remaining studies used classical statistics in a spatial context, such as group comparison of distinct zones in a hypothesis-testing framework.

\section{DISCUSSION}

The at-sea ecology of seabirds is a rapidly growing field of research. We showed that both the number of research articles published and the methods of data collection are rapidly changing. However, improvements in methodological approaches can provide greater enhancement to maximize the richness of the available data.

\section{Change in the methods, scales and units of observation}

Ship-based observations of seabird distributions still contribute to the majority of these studies, but the use of electronic-based methods is rapidly increasing. Unfortunately these 2 approaches are often used in isolation, but, if used together, they could be complementary. For example, in situ environmental data can be collected using animal-borne electronic tags to supplement ship-based data outside of the range of detection of the observation platform. Tagging data can provide a long-term time series of position data, as well as providing behavioural information that can be used to identify behavioural modes, such as diving or arearestricted searching, and their relationship to marine habitats. Such behavioural data are important to identify differences in the movement patterns and habitat utilization of different species. For example, some species may travel over considerable distances, while others may remain within a smaller home range. Such differences in behaviour may not always be apparent with traditional survey methods. However, tagging data have some significant limitations as well. Foremost among these is that data can only be collected from animals that can be tagged and that there is, as yet, no way to derive estimates of animal abundance.

The move from survey data to tracking data has also led to a fundamental change in the nature of the data collected - from an Eulerian to a Lagrangian form. In the Eulerian view, seabird observations are plotted on a grid and each cell gets a value representing a measured or estimated metric of the seabirds' presence. This is the typical grid survey type of data. In the Lagrangian view, the presence of seabirds is assimilated to moving particles in time and space. This is the typical tracking type of data. This distinction is fundamental in both the way we interpret our data and the way we deal statistically with the data (Aarts et al. 2008). Indeed, the Lagrangian approach appears particularly well suited for individual-based studies and fine-scale behaviour, whereas the Eulerian approach is more suited for population-based studies. As such, the observed trend in the way seabird distribution data are collected is associated with a reduction in temporal and spatial scales (through more precise and continuous recording of behaviour), as well as in the units of observation of the system studied (from the population to the individual). The trend towards a reduction in the scales of observation will likely continue as high-resolution GPS technology becomes more commonly used.

The diminution of the scales of observation might be seen as a consequence of the desire to pinpoint mechanistic relationships between seabirds and their environment. These mechanisms are typically expressed at the level of individual behaviour, and, therefore, they are unlikely to be captured in a 'large-scale' Eulerian study design. However, it was surprising to note that only $20.7 \%$ of the publications using electronic-based tracking of seabirds actually inferred behavioural indexes, such as area-restricted search patterns, turning rate, or feeding events (Charrassin \& Bost 2001, Catry et al. 2004, Pinaud \& Weimerskirch 2005).

The constant miniaturization of electronic devices will probably allow us to work on a wider range of seabird species, and, therefore, the trend towards a growing contribution of electronic-based studies will likely continue, especially as we learn more about previously unstudied species. However, it is highly unlikely and certainly not desirable that electronic-based methods supplant ship-based observations of seabirds, as these 2 
approaches are highly complementary. For example, ship-based observations provide opportunities to observe the context in which seabirds are foraging, including interactions with conspecifics, prey, or associations with marine mammals or flock formations, and could be complemented by electronic tagging methods that provide detailed behavioural information.

We also noted that ship-based observations have evolved towards more punctual observations rather than dedicated transects. This shift is probably a direct consequence of the increasing concerns posed by seabird bycatch in fisheries operations, which has produced a need for greater at-sea monitoring of fishing activity. Seabird ecology is therefore increasingly contributing to applied ecology, including fisheries management (Einoder 2009).

Finally, seabird observations at-sea are increasingly being regrouped (or about to be) into publicly available databases, such as (non-exhaustively) the North Pacific Pelagic Seabird database (www.absc.usgs.gov/ research/NPPSD/), the OBIS seamap project (http:// seamap.env.duke.edu/) and Movebank (www.movebank.org/). By making data accessible to a wide community of persons, it is to be anticipated that new approaches and new types of research will appear through data mining, allowing us to study seabirdenvironment interactions at larger geographical and temporal scales. In a mature field like seabird ecology, it seems unfortunate that seabird observation data are used for a few studies and then virtually disappear. We believe that public sharing of ancient data should be considered by data producers, following a number of standardized data formats and exchange protocols (see for example the Global Biodiversity Information Facility [GBIF]; http://data.gbif.org/welcome.htm).

\section{Environmental data}

Although in situ measurements of environmental variables are and have always been used in the majority of studies, we observed an increasing use of satellite remote-sensing technology. Surprisingly, remotesensing data have been used since the mid-1980s, but their use has increased only slowly until recently. This may be due to recent increases in the accessibility of these data sets to seabird ecologists, together with the increase in computing power. We also observed a surprising diversity in the environmental parameters that have been used (101 variables!). Among these, the most frequently used variable types typically described water masses (temperature, salinity, oceanic domain) or prey distributions. Occasionally, some environmental variables were used that described oceanographic structures likely to concentrate prey for forag- ing seabirds, such as thermal fronts. However, in general, these mesoscale features were a less-frequently used group of variables, including fronts, Langmuir circulation and eddies; they represented only about $5 \%$ of all variables examined. This observation is fundamental in the sense that it splits the studies into 2 philosophies: those that focus on the descriptions of habitats where seabirds are present (usually on a relatively large scale), and those that focus on processes that are expected to influence the availability of prey (presence + concentration + accessibility), and, therefore, the habitat-use strategies of seabirds (usually on a smaller scale). The choice of dependent variables is inevitably conditioned by these 2 approaches. In some cases, these approaches are closely linked and may seem similar. For example, using SST gradients (description of water mass) is related but fundamentally different from using thermal fronts or distance to a thermal front (oceanographic structure). The definition of fronts according to SST gradients is not straightforward, and implies defining thresholds and assumptions supposed or showed to be relevant to specific oceanographic processes (Miller 2004, Valavanis et al. 2005). Consequently, choosing a SST front instead of a SST gradient implies a difference in the initial assumptions about processes driving seabird distributions.

It is not surprising that relatively few studies focus on oceanographic processes, because these are complex in nature, dynamic, scale-dependent and vary over time. To overcome these issues, many researchers have used a 'shotgun' approach, incorporating a host of variables into a multivariate analysis with the hope of identifying appropriate parameters that correlate with seabird abundance. While it is assumed that these parameters are associated with prey availability and associated oceanographic processes, the actual mechanisms responsible are rarely identified. Indeed, only during the last decade, has mesoscale dynamics in the oceans emerged as an influential factor on the distribution of seabirds (Haney 1985b, 1986a,b, 1987a,b, 1988, Ribic et al. 1997, Nel et al. 2001, Weimerskirch et al. 2004, Ballance et al. 2006, Hyrenbach et al. 2006, O'Hara et al. 2006), marine turtles (Polovina et al. 2001, 2006, Lambardi et al. 2008), marine mammals (Ream et al. 2005, Campagna et al. 2006, Biuw et al. 2007), fish (Brandt 1981, Bakun 2006, Zainuddin et al. 2008), squids (Rodhouse et al. 1996, Waluda et al. 2001), zooplankton (Huntley et al. 2000, Labat et al. 2002, Strzelecki et al. 2007), phytoplankton and marine production (McGillicuddy et al. 1998, Martin 2003, Mitchell et al. 2008).

Certainly, a promising avenue of future research would be to identify the oceanographic processes and the specific mechanisms responsible for seabird distribution at various scales, a route that is distinct from the 
physical description of water masses and that is clearly an underutilized approach. These notions are, however, linked together, since it is arguable that an oceanographic structure that concentrates food at a mesoscale can be seen as a physical characteristic of a wider habitat or ecological niche. An illustration of such an approach can be seen in Fig. 2 of the paper by Tew-Kai et al. (2009).

Among all these variables, it is difficult to decide which are more important than others. Intuitively we might think of prey distribution as the major factor. However, this might depend on many factors, including (non-exhaustively) the seabird considered, the region, the breeding status, the sex and also the scale considered. For example, a procellariiform seabird might look for an oceanographic feature at large scales using its demethyl/sulfide (DMS)-sensing capabilities (a large frontal system for example), and then it might actually look for the edge of a mesoscale eddy, and only after that it would look for its prey at smaller scales. In this view, the prey factor is not necessarily the first variable used by the animal to select its habitat. Furthermore, in the case of seabirds using associations with marine mammals and schools of tunas to feed, the presence of prey might not be related to their catchability. In spite of this, obtaining real distribution maps of seabirds' prey at appropriate spatial and temporal scales is probably the holy grail of the discipline, yet obtaining these data usually remains out of reach.

Finally, the use of hydrodynamic model data and variables derived from 3-dimensional flow dynamics was virtually absent from our selection of papers. The output from these models (although they are not strictly considered data) could be used to gain environmental information on the third dimension (depth), which is virtually absent from most studies. Such contribution could help in understanding the relationships of diving seabirds with subsurface fronts or other underwater oceanographic features.

\section{Statistical analyses}

Similar to the diversity of approaches and data types found in the literature, the statistical techniques used to link seabird locations with environment variables were also highly diverse. Qualitative approaches were heavily used ( $20 \%$ of approaches), and explicit spatial statistics (statistics dependent on the position of an observation in space) were seldom utilized. The trend observed towards using Lagrangian data types was not associated with a temporal change in the statistical modelling used. This suggests that Lagrangian data (i.e. time series of spatial locations) are often used as if they were Eulerian data, in that data are treated as independent positions in space and their inherent temporal autocorrelation is often ignored. Occasionally, the temporal autocorrelation between observations is acknowledged formally, but it is most often treated as a nuisance for statistical inference. Methods do exist to overcome this problem, but these were often absent in the papers we reviewed (Legendre 1993, De Solla et al. 1999, Keitt et al. 2002, Dormann et al. 2007).

Spatial data can be described using a variety of techniques (Dale et al. 2002, Perry et al. 2002) and effort should be made to extract more information from data sets that are lacking at this stage. This would allow further standardization in the way seabird distributional data are treated, facilitating the comparison of results between studies. For example, the centre of gravity, inertia, indexes of lacunarity and variograms could be used more regularly as common descriptors of spatial distributions.

Another interesting point is that, although many individual tracks of seabirds have been gathered, very few reports have analyzed seabird behaviour with respect to the environment. Indeed, authors consider the animal's position as a consequence of the behaviour, but rarely do they use behavioural data, such as change in turning rate, speed, bearing, or any derivative thereof, in relation to the environment. Such analyses are becoming possible with the increased availability of highresolution, multi-sensor recording devices.

\section{CONCLUSIONS}

Given the trends in approaches and methodologies used in studies of the at-sea ecology of seabirds, we identified a few important topics that merit future attention. First, given the spatial nature of the data, it is important to fully utilize the appropriate statistical tools available to both describe the data and quantify the link between seabirds' locations and environmental variables. Second, seabird locations and seabird behaviour are distinct, and the latter is an important component that can be extracted from Lagrangian data types. Associating locations of particular behavioural events (e.g. area-restricted searches) with environmental parameters is a promising route that could improve our understanding of the mechanisms underlying seabird behaviour. Third, in addition to describing water masses, the choices of the environmental variables could gain by being driven by the need to identify the underlying oceanographic processes and mechanisms. Their identification implies more complex processing of the data for describing the marine environment, but there are a number of recent examples of how this might be done (Boehme et al. 2008, Chaigneau et al. 2008). 
Seabird ecology is a dynamic field of research, and its development is still growing, promising years of exciting discoveries to come.

Acknowledgements. The preparation of this review was supported by the TOPP program with support from the National Oceanographic Partnership Program ONR (Award N0001405-1-0645), the Gordon and Betty Moore, the Packard and Sloan Foundations and from the National Science Foundation Office of Polar Programs (Grants ANT-0440687 and ANT0523332).

\section{LITERATURE CITED}

Aarts G, MacKenzie M, McConnell B, Fedak M, Matthiopoulos J (2008) Estimating space-use and habitat preference from wildlife telemetry data. Ecography 31:140-160

Abello P, Arcos JM, De Sola LG (2003) Geographical patterns of seabird attendance to a research trawler along the Iberian Mediterranean coast. Sci Mar 67:69-75

Abrams RW (1983) Pelagic seabirds and trawl-fisheries in the southern Benguela Current region. Mar Ecol Prog Ser 11: 151-156

Abrams RW (1985) Environmental determinants of pelagic seabird distribution in the African sector of the southernocean. J Biogeogr 12:473-492

Ainley DG (1990) Farallon seabird patterns at the community level. In: Ainley DG, Boekelheide RJ (ed) Seabirds of the Farallon Islands: ecology, dynamics, and structure of an upwelling-system community, USA. Stanford University Press, Stanford, CA, p 349-380

Ainley DG, Anderson DW, Kelly PR (1981) Feeding ecology of marine cormorants in southwestern North America. Condor 83:120-131

Ainley DG, Sydeman WJ, Norton J (1995) Upper trophic level predators indicate interannual negative and positive anomalies in the California Current food web. Mar Ecol Prog Ser 118:69-79

Ainley DG, Jacobs SS, Ribic CA, Gaffney I (1998) Seabird distribution and oceanic features of the Amundsen and southern Bellingshausen seas. Antarct Sci 10:111-123

Ashmole NP (1971) Seabird ecology and the marine environment. In: Farner DS, King JR (eds) Avian biology, Vol 1. Academic Press, New York, p 223-286

Awkerman JA, Fukuda A, Higuchi H, Anderson DJ (2005) Foraging activity and submesoscale habitat use of waved albatrosses Phoebastria irrorata during chick-brooding period. Mar Ecol Prog Ser 291:289-300

Bakun A (2006) Front and eddies as key structures in the habitat of marine fish larvae: Opportunity, adaptive response and competitive advantages. Sciencia Marina 70S2: 105-122

Ballance LT, Pitman RL, Reilly SB (1997) Seabird community structure along a productivity gradient: importance of competition and energetic constraint. Ecology 78: 1502-1518

Ballance LT, Pitman RL, Fiedler PC (2006) Oceanographic influences on seabirds and cetaceans of the eastern tropical Pacific: a review. Prog Oceanogr 69:360-390

Benvenuti S, Bonadonna F, Dall'Antonia L, Gudmundsson G (1998) Foraging flights of breeding thick-billed murres (Uria lomvia) as revealed by bird-born direction recorders. Auk 115:57-66

Berrow SD, Wood AR, Prince PA (2000) Foraging location and range of white-chinned petrels Procellaria aequinoctialis breeding in the South Atlantic. J Avian Biol 31:303-311

Biuw M, Boehme L, Guinet C, Hindell M and others (2007) Variations in behavior and condition of a Southern Ocean top predator in relation to in situ oceanographic conditions. Proc Natl Acad Sci USA 104:13705-13710

Boehme L, Meredith MP, Thorpe SE, Biuw M, Fedak M (2008) Antarctic Circumpolar Current frontal system in the South Atlantic: monitoring using merged Argo and animalborne sensor data. J Geophys Res Oceans C09012, doi: 10.1029/2007JC004647

Brandt SB (1981) Effects of a warm-core eddy on fish distributions in the Tasman Sea off East Australia. Mar Ecol Prog Ser 6:19-33

Burger AE, Shaffer SA (2008) Perspectives in ornithology: application of tracking and data-logging technology in research and conservation of seabirds. Auk 125:253-264

- Campagna C, Piola AR, Marin MR, Lewis M, Fernandez T (2006) Southern elephant seal trajectories, fronts and eddies in the Brazil/Malvinas Confluence. Deep-Sea Res I 53:1907-1924

Catry P, Phillips RA, Phalan B, Silk JRD, Croxall JP (2004) Foraging strategies of grey-headed albatrosses Thalassarche chrysostoma: integration of movements, activity and feeding events. Mar Ecol Prog Ser 280:261-273

Chaigneau A, Gizolme A, Grados C (2008) Mesoscale eddies off Peru in altimeter records: identification algorithms and eddy spatio-temporal patterns. In: Werner F, Lough RG, Bertrand A, Guevara CR, Soler P, Csirke J, Chavez FP (eds) The northern Humboldt current system: ocean dynamics, ecosystem processes and fisheries. Prog Oceanogr 79 (special issue 2-4):106-119

Charrassin JB, Bost CA (2001) Utilisation of the oceanic habitat by king penguins over the annual cycle. Mar Ecol Prog Ser 221:285-297

Clarke J, Emmerson LM, Otahal P (2006) Environmental conditions and life history constraints determine foraging range in breeding Adélie penguins. Mar Ecol Prog Ser 310:247-261

Cooke SJ, Hinch SG, Wikelski M, Andrews RD, Kuchel LJ, Wolcott TG, Butler PJ (2004) Biotelemetry: a mechanistic approach to ecology. Trends Ecol Evol 19:334-343

Dale MRT, Dixon P, Fortin MJ, Legendre P, Myers DE, Rosenberg MS (2002) Conceptual and mathematical relationships among methods for spatial analysis. Ecography 25: 558-577

> De Solla SR, Bonduriansky R, Brooks RJ (1999) Eliminating autocorrelation reduces biological relevance of home range estimates. J Anim Ecol 68:221-234

> Dormann CF, McPherson JM, Araújo MB, Bivand R and others (2007) Methods to account for spatial autocorrelation in the analysis of species distributional data: a review. Ecography 30:609-628

- Einoder LD (2009) A review of the use of seabirds as indicators in fisheries and ecosystem management. Fish Res 95:6-13

Furness RW, Hilton G, Monteiro LR (2000) Influences of coastal habitat characteristics on the distribution of Cory's shearwaters Calonectris diomedea in the Azores archipelago. Bird Study 47:257-265

Garthe S (1997) Influence of hydrography, fishing activity, and colony location on summer seabird distribution in the south-eastern North Sea. ICES J Mar Sci 54:566-577

Haney JC (1985a) Counting seabirds at sea from ships: comments on interstudy comparisons and methodological standardization. Auk 102:897-898

Haney JC (1985b) Wintering phalaropes off the southeastern United States: application of remote sensing imagery to 
seabird habitat analysis at oceanic fronts. J Field Ornithol 56:321-333

Haney JC (1986a) Seabird affinities for Gulf Stream frontal eddies: responses of mobile marine consumers to episodic upwelling. J Mar Res 44:361-384

Haney JC (1986b) Seabird patchiness in tropical oceanic waters: the influence of Sargassum 'reefs'. Auk 103: $141-151$

Haney JC (1986c) Seabird segregation at Golf Stream frontal eddies. PSZN I: Mar Ecol 28:279-285

Haney JC (1987a) Effects of a Gulf Stream warm-core ring on summer seabird distribution in the northwest Atlantic Ocean. Limnol Oceanogr 32:665-673

Haney JC (1987b) Ocean internal waves as sources of smallscale patchiness in seabird distribution on the Blake Plateau. Auk 104:129-133

Haney JC (1988) Foraging by northern fulmars (Fulmaris glacialis) at a nearshore, anticyclonic tidal eddy in the northern Bering Sea, Alaska. Colon Waterbirds 11:318-321

Harrison CS (1982) Spring distribution of marine birds in the gulf of Alaska. Condor 84:245-254

Hunt GL Jr (1991) Occurrence of polar seabirds at sea in relation to prey concentrations and oceanographic factors. In: Sakshaug E, Hopkins CCE, Oritsland NA (eds) Proceedings of the Pro Mare Symposium on Polar Marine Ecology, Vol 10. Polar Research, Trondheim, p 553-559

Hunt GL Jr, Heinemann D, Everson I (1992) Distributions and predator-prey interactions of macaroni penguins, Antarctic fur seals, and Antarctic krill near Bird Island, South Georgia. Mar Ecol Prog Ser 86:15-30

Huntley ME, González A, Zhu Y, Zhou M, Irigoien X (2000) Zooplankton dynamics in a mesoscale eddy-jet system off California. Mar Ecol Prog Ser 201:165-178

Hyrenbach KD, Veit RR, Weimerskirch H, Hunt GL Jr (2006) Seabird associations with mesoscale eddies: the subtropical Indian Ocean. Mar Ecol Prog Ser 324:271-279

Hyrenbach KD, Veit RR, Weimerskirch H, Metzl N, Hunt GL (2007) Community structure across a large-scale ocean productivity gradient: marine bird assemblages of the Southern Indian Ocean. Deep-Sea Res I 54:1129-1145

> Hull CL, Hindell MA, Michael K (1997) Foraging zones of royal penguins during the breeding season, and their association with oceanographic features. Mar Ecol Prog Ser 153:217-228

Joiris CR (1991) Spring distribution and ecological role of seabirds and marine mammals in the Weddell sea, Antarctica. Polar Biol 11:415-424

Karnovsky NJ, Kwasniewski S, Weslawski JM, Walkusz W, Beszczynska-Moller A (2003) Foraging behavior of little auks in a heterogeneous environment. Mar Ecol Prog Ser 253:289-303

Keitt TH, Bjornstad ON, Dixon PM, Citron-Pousty S (2002) Accounting for spatial pattern when modeling organism-environment interactions. Ecography 25:616-625

Labat JP, Mayzaud P, Dallot S, Errhif A, Razouls S, Sabini S (2002) Mesoscale distribution of zooplankton in the subAntarctic frontal system in the Indian part of the Southern Ocean: a comparison between optical plankton counter and net sampling. Deep-Sea Res 49:735-749

> Lambardi P, Lutjeharms JRE, Mencacci R, Hays GC, Luschi P (2008) Influence of ocean currents on long-distance movement of leatherback sea turtles in the Southwest Indian Ocean. Mar Ecol Prog Ser 353:289-301

$>$ Legendre P (1993) Spatial autocorrelation: Trouble or new paradigm? Ecology 74:1659-1673

> Levin SA (1992) The problem of pattern and scale in ecology. Ecology 73:1943-1967
Logerwell EA, Hewitt RP, Demer DA (1998) Scale-dependent spatial variance patterns and correlations of seabirds and prey in the southeastern Bering Sea as revealed by spectral analysis. Ecography 21:212-223

- Martin AP (2003) Phytoplankton patchiness: the role of lateral stirring and mixing. Prog Oceanogr 57:125-174

> McGillicuddy DJ Jr, Robinson AR, Siegel DA, Jannasch HW and others (1998) Influence of mesoscale eddies on new production in the Sargasso Sea. Nature 394:263-266

Mehlum F, Hunt GL, Klusek Z, Decker MB (1999) Scaledependent correlations between the abundance of Brunnich's guillemots and their prey. J Anim Ecol 68:60-72

> Miller P (2004) Multi-spectral front maps for automatic detection of ocean colour features from SeaWiFS. Int J Remote Sens 25:1437-1442

> Mitchell JG, Yamazaki H, Seuront L, Wolk F, Li H (2008) Phytoplankton patch patterns: seascape anatomy in a turbulent ocean. J Mar Syst 69:247-253

Monod T (1991) Bathyfolages: plongées profondes. Réédition Actes Sud, Arles (orig. Publ. Juillard, Paris, 1954)

Navarro J, Gonzalez-Solis J (2007) Experimental increase of flying costs in a pelagic seabird: effects on foraging strategies, nutritional state and chick condition. Oecologia 151: $150-160$

Nel DC, Lutjeharms JRE, Pakhomov EA, Ansorge IJ, Ryan PG, Klages NTW (2001) Exploitation of mesoscale oceanographic features by grey-headed albatross Thalassarche chrysostoma in the southern Indian Ocean. Mar Ecol Prog Ser 217:15-26

O'Driscoll RL (1998) Description of spatial pattern in seabird distributions along line transects using neighbour K statistics. Mar Ecol Prog Ser 165:81-94

O'Hara PD, Morgan KH, Sydeman WJ (2006) Primary producer and seabird associations with AVHRR-derived sea surface temperatures and gradients in the southeastern Gulf of Alaska. Deep-Sea Res II 53:359-369

Olivier F, Wotherspoon SJ (2006) Distribution and abundance of Wilson's storm petrels Oceanites oceanicus at two locations in East Antarctica: testing habitat selection models. Polar Biol 29:878-892

> Perry JN, Liebhold AM, Rosenberg MS, Dungan J, Miriti M, Jakomulska A, Citron-Pousty S (2002) Illustrations and guidelines for selecting statistical methods for quantifying spatial patterns in ecological data. Ecography 25:578-600

Phillips RA, Silk JRD, Croxall JP, Afanasyev V (2006) Yearround distribution of white-chinned petrels from South Georgia: relationships with oceanography and fisheries. Biol Conserv 129:336-347

Pinaud D, Weimerskirch H (2005) Scale-dependent habitat use in a long-ranging central place predator. J Anim Ecol 74:852-863

Polovina JJ, Howell E, Kobayashi DR, Seki MP (2001) The transition zone chlorophyll front, a dynamic global feature defining migration and forage habitat for marine resources. Prog Oceanogr 49:469-483

Polovina J, Uchida I, Balazs G, Howell EA, Parker D, Dutton $P$ (2006) The Kuroshio Extension bifurcation region: a pelagic hotspot for juvenile loggerhead sea turtles. DeepSea Res II 53:326-339

Ream RR, Sterling JT, Loughlin TR (2005) Oceanographic features related to northern fur seal migratory movements. Deep-Sea Res II 52:823-843

Ribic CA, Ainley DG (1997) The relationships of seabird assemblages to physical habitat features in Pacific equatorial waters during spring 1984-1991. ICES J Mar Sci 54:593-599

Ribic CA, Davis R, Hess N, Peake D (1997) Distribution of seabirds in the northern Gulf of Mexico in relation to 
mesoscale features: initial observations. ICES J Mar Sci 54:545-551

Rodhouse PG, Prince PA, Trathan PN, Hatfield EMC and others (1996) Cephalopods and mesoscale oceanography at the Antarctic Polar Front: satellite tracked predators locate pelagic trophic interactions. Mar Ecol Prog Ser 136:37-50

Roycroft D, Kelly TC, Lewis LJ (2007) Behavioural interactions of seabirds with suspended mussel longlines. Aquac Int 15:25-36

Russell RW, Hunt GL, Coyle KO, Cooney RT (1992) Foraging in a fractal environment-spatial patterns in a marine predator-prey system. Landsc Ecol 7:195-209

Skov H, Durinck J (2000) Seabird distribution in relation to hydrography in the Skagerrak. Cont Shelf Res 20: 169-187

Spear LB, Ainley DG, Webb SW (2003) Distribution, abundance and behaviour of Buller's, Chatham Island and Salvin's Albatrosses off Chile and Peru. Ibis 145:253-269

Strzelecki J, Kolsow JA, Waite A (2007) Comparison of mesozooplankton communities from a pair of warm- and coldcore eddies off the coast of Western Australia. Deep-Sea Res II 54:1103-1112

Swartzman G, Hunt G (2000) Spatial association between murres (Uria spp.), puffins (Fratercula spp.) and fish shoals near Pribilof Islands, Alaska. Mar Ecol Prog Ser 206: 297-309

Tew-Kai E, Rossi V, Sudre J, Weimerskirch H and others (2009) Top marine predators track Lagrangian coherent structures. Proc Natl Acad Sci USA 106:8245-8250

Valavanis VD, Katara I, Palialexis A (2005) Marine GIS: identification of mesoscale oceanic thermal fronts. Int J Geogr Inf Sci 19:1131-1147

van Franeker JA, van den Brink NW, Bathmann UV, Pollard RT, de Barr HJW, Wolff WJ (2002) Responses of seabirds, in particular prions (Pachyptila sp.), to small-scale processes in the Antarctic Polar Front. Deep-Sea Res II 49: 3931-3950

Veit RR, Silverman ED, Everson I (1993) Aggregation patterns of pelagic predators and their principal prey, Antarctic krill, near South Georgia. J Anim Ecol 62:551-564

Villablanca R, Luna-Jorquera G, Marin VH, Garthe S,

Editorial responsibility: Jacob Gonzáles-Solís,

Barcelona, Spain
Simeone A (2007) How does a generalist seabird species use its marine habitat? The case of the kelp gull in a coastal upwelling area of the Humboldt Current. ICES J Mar Sci 64:1348-1355

- Waluda CM, Rodhouse PG, Trathan PN, Pierce GJ (2001) Remotely sensed mesoscale oceanography and the distribution of Illex argentinus in the South Atlantic. Fish Oceanogr 10:207-216

Weichler T, Garthe S, Luna-Jorquera G, Moraga J (2004) Seabird distribution on the Humboldt Current in northern Chile in relation to hydrography, productivity, and fisheries. ICES J Mar Sci 61:148-154

Weimerskirch H, Le Corre M, Jaquemet S, Potier M, Marsac F (2004) Foraging strategy of a top predator in tropical waters: great frigatebirds in the Mozambique Channel. Mar Ecol Prog Ser 275:297-308

Wilson RP, Wilson MPT, Link R, Mempel H, Adams NJ (1991) Determination of movements of African penguins Spheniscus demersus using a compass system: dead reckoning may be an alternative to telemetry. J Exp Biol 157: 557-564

- Wilson RP, Grémillet D, Syder J, Kierspel MAM and others (2002) Remote-sensing systems and seabirds: their use, abuse and potential for measuring marine environmental variables. Mar Ecol Prog Ser 228:241-261

Wilson RP, White CR, Quintana F, Halsey LG, Liebsch N, Martin GR, Butler PJ (2006) Moving towards acceleration for estimates of activity-specific metabolic rate in free-living animals: the case of the cormorant. J Anim Ecol 75: 1081-1090

Wilson RP, Liebsch N, Davies IM, Quintana F and others (2007) All at sea with animal tracks; methodological and analytical solutions for the resolution of movement. DeepSea Res II 54:193-210

Wilson RP, Shepard ELC, Liebsch N (2008) Prying into the intimate details of animal lives: use of a daily diary on animals. Endang Species Res 4:123-137

Zainuddin M, Saitoh K, Saitoh S (2008) Albacore (Thunnus alalunga) fishing ground in relation to oceanographic conditions in the western North Pacific Ocean using remotely sensed satellite data. Fish Oceanogr 17:61-73

Submitted: January 15, 2009; Accepted: June 6, 2009

Proofs received from author(s): July 28, 2009 